\title{
Photopheresis in Adults and Pediatrics
}

\author{
Hildegard Greinix
}

\subsection{Introduction}

Extracorporeal photopheresis (ECP) is a leukapheresis-based treatment that has been used during the last decades by many clinicians. Based on results of a prospective, multicenter, international clinical trial in patients with cutaneous T-cell lymphoma (CTCL), ECP was approved by the FDA as the first cellular immunotherapy for cancer in 1988 (Edelson et al. 1987). During the last decades, ECP has been investigated worldwide for prevention and treatment of a variety of T-cell-mediated diseases including acute and chronic GvHD, solid organ and tissue transplantation, systemic sclerosis, systemic lupus erythematodes, and Crohn's disease (Knobler et al. 2014). Administering ECP to patients suffering of these diseases revealed promising results both in prospective and retrospective single and multicenter clinical studies. Despite its frequent use, the mode of action of ECP remains elusive including reduction of pro-inflammatory cytokines and induction of anti-inflammatory cytokines and modulation of immune cell populations.

H. Greinix $(\bowtie)$

Division of Hematology, Medical University of Graz, Graz, Austria

e-mail: hildegard.greinix@medunigraz.at

\subsection{Technical Aspects}

During ECP the patient's blood is collected via an antecubital vein or via a permanent catheter, and the white blood cells are separated from the red blood cells and plasma by centrifugation in a device that is specifically constructed for the procedure (Knobler et al. 2014; Schoonemann 2003). Collected mononuclear cells (MNCs) using either continuous or discontinuous cell separators are then exposed ex vivo to a photosensitizing agent, 8-methoxypsoralen (8-MOP), which is added directly to the buffy coat/plasma fraction followed by photoactivation with ultraviolet $\mathrm{A}$ (UV-A) irradiation and then reinfusion of the photoactivated product (Schoonemann 2003).

ECP has originally been developed as a single procedure which combines the separation of the MNCs from the whole blood with irradiation of the 8-MOP-treated leukapheresis products within a single machine ("closed system of ECP"). The "offline technique" (two-step method) of ECP treatment includes as the first step cell separation with a standard blood cell separator that can also be used for the collection of peripheral blood stem cells. The apheresis product is transferred into another disposable, 8-MOP is added, and irradiation is performed with a separate machine at a dosage of $2 \mathrm{~J} / \mathrm{cm}^{2}$. After irradiation transfusion of the treated cells is carried out manually by a standard transfusion set. Both ECP techniques have demonstrated clinical efficacy, but almost all clinical studies have been performed with the single 
ECP technique, and studies comparing both systems are almost completely lacking (Schoonemann 2003; Andreu et al. 1994; Brosig et al. 2016).

\subsection{Results of ECP in Acute GvHD}

To date, no consensus on the optimal choice of agents for salvage therapy of steroid-refractory acute GvHD has been reached, and treatment choices are based on physician's experience, risk of toxicity and potential exacerbation of preexisting comorbidity, interactions with other agents, and ease of use (Martin et al. 2012). During the last years, more and more HSCT centers have administered ECP to patients with steroidrefractory acute GvHD. Results of larger prospective studies on the use of ECP in this indication are shown in Table 66.1. The intensified schedule of ECP with two to three treatments per week on a weekly basis significantly improved response rates in patients with GI involvement and grade IV acute GvHD (Greinix et al. 2006).

In a systematic review of prospective studies including 6 studies with 103 patients given ECP for steroid-refractory acute GvHD, an overall response rate (ORR) of 69\% was achieved including ORR for skin, liver, and GI involvement of $84 \%, 55 \%$, and $65 \%$, respectively (Abu-Dalle et al. 2014). Compared to anticytokine treatment, administration of ECP for steroid-refractory acute GvHD not only achieved significantly higher ORR (66\% vs 32\%) and CR (54\% vs $20 \%$ ), but ECP was also an independent predictor of response and survival and was associated with significantly lower NRM and superior survival in steroid-refractory grade II acute GvHD (Jagasia et al. 2013). Compared to other IST, ECP has an excellent safety profile with limited toxicity concerns, no increased concerns for viral reactivations, and no documented interaction with other drugs (Martin et al. 2012).

\subsection{Results of ECP in Chronic GvHD}

Although many therapeutic options have been reported for salvage treatment of steroidrefractory chronic GvHD, no single class of IS agent has been established as standard therapy (Wolff et al. 2011). ECP represents a frequently used therapeutic approach for treatment of chronic GvHD patients failing corticosteroids (Table 66.2) (Knobler et al. 2014; Wolff et al. 2011; Greinix et al. 1998; Flowers et al. 2008; Jagasia et al. 2009; Greinix et al. 2011). Most of the clinical experience in ECP treatment of steroid-refractory chronic GvHD patients is based on retrospective analyses with consistently high response rates in up to $80 \%$ of patients with cutaneous manifestations and substantial improvement in sclerodermatous skin involvement (Knobler et al. 2014; Wolff et al. 2011).

Table 66.1 Results of second-line treatment of acute GvHD using extracorporeal photopheresis

\begin{tabular}{|l|l|l|l|l|l|}
\hline Author (year) & No. of patients & CR skin no. (\%) & CR liver no. (\%) & CR gut no. (\%) & OS\% \\
\hline Salvaneschi (2001) & 9 & $6 / 9(67)$ & $1 / 3(33)$ & $3 / 5(60)$ & 67 \\
\hline Dall'Amico (2002) & 14 & $10 / 14(71)$ & $4 / 7(57)$ & $6 / 10(60)$ & 57 \\
\hline Messina et al. (2003) & 33 & $25 / 33(76)$ & $9 / 15(60)$ & $15 / 20(75)$ & 69 at $5 \mathrm{y}$ \\
\hline Greinix et al. (2006) & 59 & $47 / 57(82)$ & $14 / 23(61)$ & $9 / 15(60)$ & 47 at $5 \mathrm{y}$ \\
\hline Garban (2005) & 12 & $8 / 12(67)$ & $0 / 2(0)$ & $2 / 5(40)$ & 42 \\
\hline Kanold (2007) & 12 & $9 / 10(90)$ & $5 / 9(56)$ & $5 / 6(83)$ & 75 at $8.5 \mathrm{~m}$ \\
\hline Calore (2008) & 15 & $12 / 13(92)$ & & $14 / 14(100)$ & 85 at $5 \mathrm{y}$ \\
\hline Perfetti (2008) & 23 & $15 / 23(65)$ & $3 / 11(27)$ & $8 / 20(40)$ & 48 at $37 \mathrm{~m}$ \\
\hline Gonzalez-Vicent (2008) & 8 & $8 / 8(100)$ & $2 / 2(100)$ & $4 / 7(57)$ & 38 \\
\hline Perotti (2010) & 50 & $39 / 47(83)(1)$ & $16 / 24(67)(1)$ & $8 / 11(73)(1)$ & 64 at $1 \mathrm{y}$ \\
\hline Jagasia (2013) & 57 & $38 / 57(67)(1)$ & $38 / 57(67)(1)$ & $38 / 57(67)(1)$ & 59 at $2 \mathrm{y}$ \\
\hline Calore (2015) & 72 & $50 / 64(78)$ & $10 / 12(84)$ & $42 / 55(76)$ & 71 at $5 \mathrm{y}$ \\
\hline
\end{tabular}

Abbreviations: No number, $C R$ complete resolution, $O S$ overall survival, $y$ years, $m$ months

Results were provided as complete and partial resolution. 
Table 66.2 Results of use of extracorporeal photopheresis in chronic GvHD

\begin{tabular}{|l|l|l|l|l|l|}
\hline Author (year) & No of patients & CR/PR skin (\%) & CR/PR liver (\%) & CR/PR oral (\%) & ORR (\%) \\
\hline Greinix et al. (1998) & 15 & 80 & 70 & 100 & na \\
\hline Salvaneschi (2001) & 14 & 83 & 67 & 67 & 64 \\
\hline Messina (2003) & 44 & 56 & 60 & 21 & 57 \\
\hline Seaton (2003) & 28 & 48 & 32 & na & 36 \\
\hline Apisarnthanarax (2003) & 32 & 59 & 0 & 46 & 56 \\
\hline Foss (2005) & 25 & 64 & 0 & 92 & 64 \\
\hline Rubegni (2005) & 32 & 81 & 77 & 95 & 69 \\
\hline Greinix (2006) & 47 & 93 & 84 & 78 & 61 \\
\hline Couriel (2006) & 71 & 57 & 71 & 86 & 50 \\
\hline Kanold (2007) & 15 & 75 & 82 & 78 & 73 \\
\hline Perseghin (2007) & 25 & 67 & 67 & 53 & 40 \\
\hline Flowers (2008) & 48 & 40 & 29 & & 65 \\
\hline Jagasia (2009) & 43 & & & 80 & 69 \\
\hline Perotti (2010) & 23 & 96 & 100 & 91 & 74 \\
\hline Dignan (2012) & 82 & 92 & na & 70 & na \\
\hline Greinix (2011) & 29 & 31 & 50 & na & 81 \\
\hline Del Fante (2016) & 102 & na & 67 & na & 86 \\
\hline Ussowicz (2013) & 13 & 59 & 89 & 60 & 69 \\
\hline Hautmann (2013) & 32 & 65 & -29 & 44 \\
\hline Dignan (2014) & 38 & & 100 & 50
\end{tabular}

Abbreviations: No number, $C R$ complete resolution, $P R$ partial resolution, $O R R$ overall response rate, na not available

In a multicenter, randomized, controlled, prospective phase II study of ECP in 95 patients with steroid-refractory/dependent/intolerant chronic GvHD, significantly more patients in the ECP arm achieved a complete or partial response of cutaneous manifestations $(p<0.001)$ as well as a 50\% reduction in steroid dose and at least a $25 \%$ decrease in total skin score $(p=0.04)$ by week 12 (Greinix et al. 1998). A steroid-sparing effect of ECP has also been reported by other investigators (Knobler et al. 2014; Wolff et al. 2011; Flowers et al. 2008; Jagasia et al. 2009).

In a systematic review of prospective studies on the use of ECP in patients with chronic GvHD, an ORR of $71 \%$ in cutaneous, $62 \%$ in GI, $58 \%$ in hepatic, $63 \%$ in oral mucosal, and $45 \%$ in musculoskeletal manifestations of chronic GvHD was reported (Abu-Dalle et al. 2014). Rate of IS discontinuation was $23 \%$ and ECP was tolerated excellently. In another metaanalysis high response rates in cutaneous and extracutaneous manifestations of chronic GvHD including $48 \%$ of responses in lung involvement were confirmed (Del Fante et al.
2016). The ECP schedule in chronic GvHD is empirical ranging from multiple treatments per week on a weekly basis to two treatments biweekly and in case of response prolongation of the treatment interval to 4-6 weeks, respectively. No clear association between ECP dose intensity and response has been reported. Higher response rates were achieved in steroidrefractory patients given ECP earlier in the course of their disease (Malik et al. 2014; Messina et al. 2003). Improvements in quality of life and survival in ECP responders have been reported (Knobler et al. 2014; Wolff et al. 2011; Greinix et al. 1998; Malik et al. 2014; Messina et al. 2003).

ECP is a safe and efficacious treatment for patients with chronic GvHD with steroid-sparing capacity. Transient hypotension during treatment and mild anemia and/or thrombocytopenia have been reported as side effects of ECP. Prospective clinical studies are warranted to assess the efficacy of ECP in well-defined cohorts of chronic GvHD patients treated earlier in the course of their disease. Recently, Jagasia and colleagues reported first results of a 
randomized, controlled, multicenter study in NIH-defined moderate/severe chronic GvHD patients given ECP in the study arm in combination with standard of care IS (Jagasia et al. 2017). Besides an ORR of $74 \%$, and thus, a promising efficacy ECP demonstrated to be safe and tolerated well.

\subsection{Conclusions}

ECP has been used for over 30 years in the treatment of CTCL, acute and chronic GvHD, and solid organ transplant rejection. Multiple scientific organizations recommend its use due to ECP's efficacy and excellent safety profile (Knobler et al. 2014). Due to the lack of interactions with other agents and the avoidance of general IS, ECP compares favorably with other IS strategies, supporting its increasingly frequent use as second-line therapy of steroid-refractory/ dependent acute and chronic GvHD. Of note, the corticosteroid-sparing potential of ECP has been confirmed in numerous retrospective and prospective studies and translates into immediate clinical benefit for patients with GvHD as well as a reduction of transplant-associated morbidity and mortality.

No general recommendation can be made on treatment schedule due to missing evidence. Ideally, ECP treatment should be initiated as early as possible after the indication is confirmed. Especially in patients with steroid-refractory acute GvHD, earlier treatment onset and an intensified weekly ECP schedule resulted in improved response rates and patients' outcome. Prospective studies on the use of ECP as upfront treatment in GvHD are warranted as well as its investigation for prophylactic/preemptive use during allo-HSCT.

\section{Key Points}

- ECP is a safe and efficacious adjunct therapy of steroid-refractory acute and chronic GvHD.

- Results in upfront therapy of chronic GvHD are promising.

\section{References}

Abu-Dalle I, Reljic T, Nishihori T, et al. Extracorporeal photopheresis in steroid-refractory acute or chronic graft-versus-host disease: Results of a systematic review of prospective studies. Biol Blood Marrow Transplant. 2014;20:1677-86.

Andreu G, Leon A, Heshmati F, et al. Extracorporeal photochemotherapy: evaluation of two techniques and use in connective tissue disorders. Transfus Sci. 1994;15:443-54.

Apisarnthanarax N, Donato M, Korbling M, et al. Extracorporeal photopheresis therapy in the management of steroid-refractory or steroid-dependent cutaneous chronic graft-versus- host disease after allogeneic stem cell transplantation: feasibility and results. Bone Marrow Transplant. 2003;31:459-65.

Brosig A, Hähnel V, Orsó E, et al. Technical comparison of four different photopheresis systems. Transfusion. 2016;56:2510-9.

Calore E, Calo A, Tridello G, et al. Extracorporeal photochemotherapy may improve outcome in children with acute GVHD. Bone Marrow Transplant. 2008;42:421-5.

Calore E, Marson P, Pillon M, et al. Treatment of acute graft-versus-host disease in childhood with extracorporeal photochemotherapy/photopheresis: the Padova experience. Biol Blood Marrow Transplant. 2015;21:1963-72.

Couriel DR, Hosing C, Saliba R, et al. Extracorporeal photochemotherapy for the treatment of steroidresistant chronic GVHD. Blood. 2006;107:3074-80.

Dall'Amico R, Messina C. Extracorporeal photochemotherapy for the treatment of graft-versus-host disease. Ther Apher. 2002;6:296-304.

Del Fante C, Galasso T, Bernasconi P, et al. Extracorporeal photopheresis as a new supportive therapy for bronchiolitis obliterans syndrome after allogeneic stem cell transplantation. Bone Marrow Transplant. 2016;51:728-31.

Dignan FL, Greenblatt D, Cox M, et al. Efficacy of bimonthly extracorporeal photopheresis in refractory chronic mucocutaneous GVHD. Bone Marrow Transplant. 2012;47:824-30.

Dignan FL, Aguilar S, Scarisbrick JJ, et al. Impact of extracorporeal photopheresis on skin scores and quality of life in patients with steroid-refractory chronic GVHD. Bone Marrow Transplant. 2014;49:704-8.

Edelson R, Berger C, Gasparro F, et al. Treatment of cutaneous T-cell lymphoma by extracorporeal photochemotherapy. Preliminary results. N Engl J Med. 1987;316:297-303.

Flowers MED, Apperley J, von Besien K, et al. A multicenter prospective phase 2 randomized study of extracorporeal photopheresis for treatment of chronic graft-versus-host disease. Blood. 2008;112:2667-74.

Foss FM, DiVenuti GM, Chin K, et al. Prospective study of extracorporeal photopheresis in steroid-refractory or steroid-resistant extensive chronic graft-versus-host disease: analysis of response and survival incorporating prognostic factors. Bone Marrow Transplant. 2005;35:1187-93. 
Garban F, Drillat P, Makowski C, et al. Extracorporeal chemophototherapy for the treatment of graft-versushost disease: hematologic consequences of short-term, intensive courses. Haematologica. 2005;90:1096-101.

Greinix HT, Volc-Platzer B, Rabitsch W, et al. Successful use of extracorporeal photochemotherapy in the treatment of severe acute and chronic graft-versus-host disease. Blood. 1998;92:3098-104.

Greinix HT, Knobler RM, Worel N, et al. The effect of intensified extracorporeal photochemotherapy on long-term survival in patients with severe acute graft-versus-host disease. Haematologica. 2006;91: 405-8.

Greinix HT, van Besien K, Elmaagacli AH, et al. Progressive improvement in cutaneous and extracutaneous chronic graft-versus-host disease after a 24-week course of extracorporeal photopheresisresults of a crossover randomized study. Biol Blood Marrow Transplant. 2011;17:1775-82.

Gonzalez-Vicent M, Ramirez M, Perez A, et al. Extracorporeal photochemotherapy for steroid-refractory graft-versus-host disease in low-weight pediatric patients. Immunomodulatory effects and clinical outcome. Haematologica. 2008;93:1278-80.

Hautmann AH, Wolff D, Hahn J, et al. Extracorporeal photopheresis in 62 patients with acute and chronic GVHD: Results of treatment with the COBE Spectra system. Bone Marrow Transplant. 2013;48: 439-45.

Jagasia MH, Savani BN, Stricklin G, et al. Classic and overlap chronic graft-versus-host disease (cGVHD) is associated with superior outcome after extracorporeal photopheresis (ECP). Biol Blood Marrow Transplant. 2009; $15: 1288-95$.

Jagasia M, Greinix H, Robin M, et al. Extracorporeal photopheresis versus anticytokine therapy as a secondline treatment for steroid-refractory acute GVHD: a multicentre comparative analysis. Biol Blood Marrow Transplant. 2013;19:1124-33.

Jagasia M, Greinix H, Scheid C, et al. A randomized controlled study of extracorporeal photopheresis (ECP) therapy with UVADEX (methoxsalen) for National Institutes of Health (NIH)-graded moderate to severe chronic graft-versus-host disease (cGvHD). Blood. 2017;130:1970.

Kanold J, Merlin E, Halle P, et al. Photopheresis in pediatric graft-versus- host disease after allogeneic marrow transplantation: clinical practice guidelines based onfield experience and review of the literature. Transfusion. 2007;47:2276-89.
Knobler R, Berlin G, Calzavara-Pinton P, et al. Guidelines on the use of extracorporeal photopheresis. JEADV. 2014;28(Suppl 1):1-37.

Malik MI, Litzow M, Hogan W, et al. Extracorporeal photopheresis for chronic graft-versus-host disease: a systematic review and meta-analysis. Blood Res. 2014;49:100-6.

Martin PJ, Rizzo JD, Wingard JR, et al. First-and secondline systemic treatment of acute graft-versus-host disease: recommendations of the American Society of Blood and Marrow Transplantation. Biol Blood Marrow Transplant. 2012;18:1150-63.

Messina C, Locatelli F, Lanino E, et al. Extracorporeal photochemotherapy for paediatric patients with graftversus-host disease after haematopoietic stem cell transplantation. Br J Haematol. 2003;122:118-27.

Perfetti P, Carlier P, Strada P, et al. Extracorporeal photopheresis for the treatment of steroid refractory acute GVHD. Bone Marrow Transplant. 2008;42:609-17.

Perotti C, Del Fante C, Tinelli C, et al. Extracorporeal photochemotherapy in graft- versus-host disease: a longitudinal study on factors influencing the response and survival in pediatric patients. Transfusion. 2010;50:1359-69.

Perseghin P, Galimberti S, Balduzzi A, et al. Extracorporeal photochemo-therapy for the treatment of chronic graft-versus-host disease: Trend for a possible cell dose-related effect? Ther Apher Dial. 2007;11:85-93.

Rubegni P, Cuccia A, Sbano P, et al. Role of extracorporeal photochemotherapy in patients with refractory chronic graft-versus-host disease. $\mathrm{Br} \mathrm{J}$ Haematol. 2005;130:271-5.

Salvaneschi L, Perotti C, Zecca M, et al. Extracorporeal photochemotherapy for treatment of acute and chronic GVHD in childhood. Transfusion. 2001;41:1299-305.

Schoonemann F. Extracorporeal photopheresis technical aspects. Transfus Apher Sci. 2003;28:51-61.

Seaton ED, Szydlo RM, Kanfer E, et al. Influence of extracorporeal photopheresis on clinical and laboratory parameters in chronic graft-versus-host disease and analysis of predictors of response. Blood. 2003; 102:1217-23.

Ussowicz M, Musiał J, Mielcarek M, et al. Steroidsparing effect of extracorporeal photopheresis in the therapy of graft-versus-host disease after allogeneic hematopoietic stem cell transplantation. Transplant Proc. 2013;45:3375-80.

Wolff D, Schleuning M, von Harsdorf S, et al. Consensus conference on clinical practice in chronic GVHD: second-line treatment of chronic graft-versus-host disease. Biol Blood Marrow Transplant. 2011;17:1-17.

Open Access This chapter is licensed under the terms of the Creative Commons Attribution 4.0 International License (http://creativecommons.org/licenses/by/4.0/), which permits use, sharing, adaptation, distribution and reproduction in any medium or format, as long as you give appropriate credit to the original author(s) and the source, provide a link to the Creative Commons license and indicate if changes were made.

The images or other third party material in this chapter are included in the chapter's Creative Commons license, unless indicated otherwise in a credit line to the material. If material is not included in the chapter's Creative Commons license and your intended use is not permitted by statutory regulation or exceeds the permitted use, you will need to obtain permission directly from the copyright holder. 